Andrews University

Digital Commons @ Andrews University

Master's Theses

Graduate Research

1974

\title{
A Multi-Sensory Approach to Teaching Spelling to Learning Disabled Children
}

Judith M. Meuleman

Follow this and additional works at: https://digitalcommons.andrews.edu/theses

Part of the Disability and Equity in Education Commons, and the Special Education and Teaching Commons

\section{Recommended Citation}

Meuleman, Judith M., "A Multi-Sensory Approach to Teaching Spelling to Learning Disabled Children" (1974). Master's Theses. 168.

https://dx.doi.org/10.32597/theses/168

https://digitalcommons.andrews.edu/theses/168

This Thesis is brought to you for free and open access by the Graduate Research at Digital Commons @ Andrews University. It has been accepted for inclusion in Master's Theses by an authorized administrator of Digital Commons @ Andrews University. For more information, please contact repository@andrews.edu. 


\section{ABSTRACT OF GRADUATE STUDENT RESEARCH}

Thesis

Andrews University

Department of Education

\section{Title: A MULTI-SENSORY APPROACH TO TEACHING SPELLING TO LEARNING DISABLED CHILDREN}

Name of researcher: Judith M. Meuleman

Name and title of faculty advisors: Conrad A. Reichert, Ph.D., Chairman Wilfred G. A. Futcher, Ph.D. Ruth Murdoch, Ed.D.

Date completed: September 1974

Problem

Learning disabled children are receiving increasing attention, for despite an intelligence quotient within the normal range, they are not achieving in school as well as their peers. The reasons offered for this phenomenon seem to relate to perceptual problems. Specific learning disabilities occur in reading, arithmetic, spelling, handwriting and other motor coordination areas.

This study investigates the effect of a multi-sensory method. of teaching spelling to learning disabled children using sandpaper letters to utilize the tactile and kinesthetic sensory modalities.

\section{Method}

Unfamiliar spelling words were taught to 40 learning disabled children, 38 boys and 2 girls. The children were matched by age. One group was taught traditionally and the other group was taught using. 
sandpaper letters. The pretest and posttest were scored and an analysis of covariance and a regression analysis of the independent variables was performed on the data. An analysis was also made on the types of errors the children made.

\section{Results}

An analysis of the data showed that the experimental group did not do any better than the control group nor were particular types of errors helped significantly by the experimental method.

\section{Conclusions}

Although the experimental group did not do significantly better than the control group, it would be premature to conclude that adding a tactile, kinesthetic element to teaching spelling is worthless. Many factors could have had an influence on the experiment. Further studies are needed to make a judgment of the applicability of this remedial method. 
Andrews University

School of Graduate Studies

A MULTI-SENSORY APPROACH TO TEACHING SPELLING

TO LEARNING DISABLED CHILDREN

\author{
A Thesis
}

Presented in Partial Fulfillment

of the Requirements for the Degree

Master of Arts

by

Judith M. Meuleman

September 1974

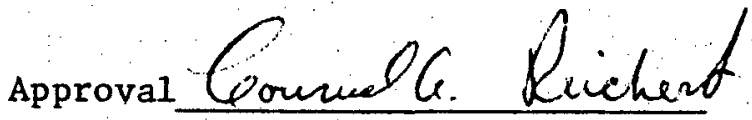


TABLE OF CONTENTS

Page

LIST OF TABLES .................... . . . $i i i$

PREFACE ........................ . . . iv

Chapter

I. INTRODUCTION ................... 1

Statement of the Problem .. . . . . . . . . . 1

The Purpose of the Study . . . . . . . . . . 1

II. REVIEW OF THE LITERATURE . . . . . . . . . . . . 3

Description .................. 3

Diagnosis . . . . ............ . . . 6

Perception ................ 10

Visual Perception............... 11

Auditory Perception ............. . . 12

Motor Problems ............... . . 14

Perceptual Training ............. 15

Specific Learning Disabilities ......... 18

School Intervention Methods . . . . . . . . 22

Multi-Sensory Approach to Spelling Remediation . . 22

Hypothesis ................ 24

III. METHODOLOGY . . . . ........... 25

Population and Sample . . ......... 25

Independent Variables . . . . . . . . . 25

Distribution of the Independent Variables..... 26

Procedure .. . . . . . . . . . . 26

IV. ANALYSIS OF THE DATA . . . . . . . . . 30

Pretest-Posttest Scores Analysis . . . . . . 30

Types of Error Scores Analysis . . . . . . 35

v. SUMMARY AND CONCLUSIONS . . . . . . . . . . . 39

BIBLIOGRAPHY . . . . . . . . . . . . . . . 41 


\section{LIST OF TABLES}

Table

1. Etiological Factors in the Reading Disabilities of 146 Pupils of Average

Intelligence Referred to a Reading Clinic . . . . 19

2. Summary of the Data . . . . . . . . . 31

3. Means and Standard Deviations . . . . . . . 32

4. Summary Table of Step-Wise Regression No. 1 . . . 33

5. Correlation Matrix . . . . . . . . . . 33

6. Summary Table of Step-Wise Regression No. 2 ..... 34

7. Summary Table of Step-Wise Regression No. 3... . 34

8. Summary Table of Step-Wise Regression No. 4 ... . 34

9. F Ratios for Subgroups ............ 35

10. Types of Error . . . . . . . . . . . . 36

11. Types of Error Scores . . . . . . . . . 37

12. F Ratios of Type 1 and Type 4 Error Scores . . . . 38

13. Summary of F Ratios of Subgroups . . . . . 38 
PREFACE

Learning disabilities is a fairly new field receiving much publicity in the past few years. Many new and creative methods are being attempted so that these children can learn and reach their potentials, but it is difficult to evaluate different methods because research data are lacking. This report reviews the recent literature and attempts to analyze a method of teaching spelling to these children.

Thanks are expressed to Nelson Mosher, Director of Special Education, Niles, Michigan Schools; Ken Horn and Sue Girkin, Learning Disabilities teachers, Niles, Michigan; Gloria Vanderbeck, Director of Curriculum, Lakeshore Schools, Stevensville, Michigan; Richard Peterson; principal at Hollywood School; Les Collins, principal at Stevensville School; Nancy Stëifel and Nita Turner, Resource Room teachers, Lakeshore Schools; and all the classroom teachers involved for their help and cooperation. Thanks are expressed to Dr. Lawrence McNitt, Mathematics professor as well as my thesis committee, Dr. Conrad Reichert, Dr. Ruth Murdoch and Dr. Wilfred G. A. Futcher for all of their advice and encouragement. 
CHAPTER I

INTRODUCTION

\section{Statement of the Problem}

A learning disability is defined as a disorder in a particular school area, such as language arts, arithmetic, gross and fine motor skills, which was possibly caused by minimal brain damage, emotional disturbance or maturational lag. There are a variety of tests used to diagnose a learning dișabled child. Most of these evaluate visual, auditory and motor perception. Perception is the intermediate step between sensory impression reception and integration and storage in the brain. Most learning disabled children are below average in visual perception, auditory perception or motor perception, which means that the sensory impressions these children receive are not accurate, but distorted in some way. Various training methods have been devised to strengthen these impairments thus hoping to remediate the school problem area. Because learning disability symptoms are fairly subtle, it has been only recently that the problem has been pin-pointed and the schools have become interested in trying to help these children achleve academic success.

\section{The Purpose of the Study}

The purpose of the study was to investigate a method of teaching spelling to learning disabled children utilizing a multi-sensory approach. 
Spelling lessons usually rely upon two sensory modes in the presentation--visual and auditory. Most learning disabled children have visual or auditory perception impairments and are consequently at a disadvantage in learning to spell. It was felt that, if one sensory modality (e.g., visual perception) is impaired then another sense might compensate for the impairment. Utilizing a multi-sensory approach to spelling compensates for a visual or auditory impairment. The multi-sensory approach consists of adding a tactile (touch) sense and kinesthetic sense (perception obtained through body movements and muscle feeling) to the traditional sight-sound approach. This was accomplished by using sandpaper letters to make new spelling words and having the child trace them. 
CHAPTER II

\author{
REVIEW OF THE LITERATURE
}

\title{
Description
}

A learning disability is defined as a retardation, disorder, or delayed development in one or more of the processes of speech, language, reading, writing, arithmetic or other school subjects resulting from a psychological handicap caused by a possible cerebral dysfunction and/or emotional or behavior disturbances. It is not a result of mental retardation, sensory deprivation, or cultural or instructional factors (Ferinden, VanHande1, Kovalinsky, 1971, p. 193).

Learning disabled children account for approximately one per cent of the school population as reported by the Bureau of Education for the Handicapped. Estimates from school principals are much higher, some as high as 2.5 per cent nationally and 3.2 per cent in the elementary schools (Froomkin, 1972, pp. 40-1). Boys are more frequently affected $\mathrm{by}_{\mathrm{y}}$, the syndrome in a ratio of 3 or 4 to 1 (Tarnopol, 1969, p. 7). The problem is so subtle that it has been recognized for only about twenty years. Cerebral dysfunction or minimal brain damage is thought to be a possible cause of learning disabilities, and is widely used interchangeably with the term "learning disabilities." Lerner feels that "learning disabilities" is a more satisfactory term because it emphasizes not a presumed cause (neurological damage), but the problem the child faces (1971, p. 21). The following scale shows the medical symptoms of both minimal and major brain damage (Ibid., p. 19). 
Minimal

1. Impairment of the fine movement of coordination

2. Electroencephalographic abnormalities without actual seizures

3. Deviation in attention, activity level, impulse control and affect

4. Specific and circumscribed perceptual, intellectual and memory deficits

5. Nonperipheral impairments of vision, hearing, haptics and speech
Major

Cerebra1 palsies

Epilepsies

Autism and other gross disorders Mental subnormalities

B1indness, deafness and severe aphasia

Reading disabilities, arithmetic disabilities, poor ability to organize work and frequent confusion with instructions are problems of ten associated with minimal brain damage (Lacey, 1970, p. 206).

In many learning disabled children symptoms of emotional disturbance occur. "The child is likely to perceive the difference between himself and normal children and experience a profound sense of inferiority (Anderson, 1970, p. 145)." Compensatory mechanisms can develop which are directed toward useless goals, such as; incompetency and helplessness, attention-getting behavior, power or revenge (Ibid., p. 145). A poor self-concept and poor school performance can lead a child to seek attention and acceptance by his friends through delinquent behavior, truancy or other anti-social acts (Brown, 1969, p. 100). The development of emotional problems and their resultant behavior must be treated with the learning disabilities so that a we11-adjusted adult can emerge.

Anderson explains three models which emphasize different possible causes and therefore different treatments for learning disabilities (1970, p. 145). The first model is called the Psychogenic Model. This is based on the premise that emotional or psychogenic factors are 
causing the disability. The second model, Neurological Model, assumes that minimal brain dysfunction causes the disabilities. Anderson feels that the third or Neuropsychogenic Model is the most valid. This model states that emotional and neurological symptoms must be treated to remediate the learning disabilities.

Another causative theory is mentioned in the literature. This is the maturational lag theory. The maturational lag theory is based on Piaget's stages of development. The proponents feel it is essential that a child be given opportunities to stabilize behavior and thought at each particular stage of development (Lerner, 1971, pp. 239-40). Timing of beginning school, for instance, is very important. Most children naturally tend to do those things in which they are comfortable and avoid activities which are not comfortable. This is a good indication of the child's readiness for various activities (Ibid., p. 241). Masland feels that children with learning disabilities have maturational deviations which are permanent (ed. Tarnopol, 1969, p. 78). Some characteristics of maturational variations are (Waugh \& Bush, 1971, p. 10):

1. Frequent lags in developmental milestones, e.g., motor, language

2. Generalized maturational lag during early school years

3. Physically immature

In summary, some of the characteristics of the learning disabled child are (Brown, 1969; Kahn, 1969; Lukens, ed. Tarnopol, 1969; Schwalb, 1969; Tarnopol, 1969; Waugh and Bush, 1971):

1. reading, spelling, arithmetic, speech disabilities

2. poor writing, printing or drawing ability and copying from the blackboard

3. variability in performance from day to day or even hour to hour and from subject to subject

4. poor ability to organize work 
5. slowness in finishing work

6. frequent confusion about instructions

7. hyperactivity--overactive, either in purposeless or in planned body activity

8. impulsivity--uncontrollable tendency to act, of ten to act in a dangerous, foolish or purposeless way in opposition to rules or direction

9. short attention span--distractibility

10. perseveration--abnormal persistence in one activity, verbal expression, body motion or idea

11. memory problems

12. motor problems--mixed laterality (handedness), right-left disorientation, coordination

13. perceptual deficits (visual, auditory, kinesthetic, tactile)

14. emotional lability--variable, fragile, brittle feelings or mood; too elated, too sad, too much remorse, too frustrated, too angry; extreme and rapid swings in mood

15. aggressiveness

16. immaturity

17. poor interpersonal relationships

18. difficulty with change or the lack of structure

19. anxiety

20. Low frustration or stress tolerance

\section{Diagnosis}

The learning disabilities syndrome has so many varied expressions, and the child can have so many different behavior patterns that it is difficult to diagnose it. The following is a list of the more commonly used tests in identification of learning disabled children (Coleman \& Dawson, 1969; Sabatino, 1969; Tarnopo1, 1969):

1. Illinois Test of Psycholinguistic Abilities--provides a profile of auditory-linguistic and visual-1inguistic strengths and weaknesses.

2. Frostig Test of Visual Perception--differentiates the various problem areas in visual perception.

3. Purdue Perceptual Motor Survey--identifies problem areas such as confused directionality, mixed.laterality, confusion about body parts.

4. Wepman Test of Auditory Discrimination

5. Wechsler Intelligence Scale for Children

6. Bender-Gestalt Test--developed to identify children with visual-motor perception problems and minimal neurological impairment. 
7. Draw-a-Person Test

8. The Gray Oral Reading Test

9. The Wide Range Achievement Test

Unless a test is item analyzed, visual-perceptual-motor dysfunction is not revealed. The child's errors must be categorized to find out if there is a particular problem. Many times poor scores on a test are not thought to be related to perceptual problems but instead caused by a general dullness of the child (Coleman \& Dawson, 1969).

Test performance not only shows what a child knows, but also what he does not know. The pattern of errors may be more important in planning an educational program for the child than the total score (Ibid., p. 249).

Rice states that an achievement standard score 15 or more points below the full scale I.Q. Indicates a significant deficit (1970, p. 151). A deviation of four or more years between the child's best and worse skills is prevalent in learning disabled children (Lerner, 1971, p. 214). Some indications of learning disabilities on test performance follows (Waugh \& Bush, 1971, p. 7):

1. Spotty or patchy intellectual deficits; achievement low in some areas, high in others

2. Below mental age level on drawing tests

3. Geometric figure drawings poor for age and measured intelligence

4. Poor performance on block design and marble board tests

5. Poor showing on group tests and on daily classroom examinations which require reading.

Group tests assume the inherent presence of certain skills and abilities; e.g., 1) that the child has adequate visual acuity and visual-perceptual skills, 2) that the child has adequate auditory acuity and auditory perceptual skills, 3) that the child can sit still and attend to the task at hand for at least twenty minutes, 4) that the 
child can understand the vocabulary used in the oral directions given, 5) that the child can hold a pencil and mark with it and 6) that the child understands the spatial concepts of row, top, bottom, circle, X, below, above, around, etc. (Coleman \& Dawson, 1969, p. 247).

As pointed out earlier, there is quite a disparity in test subskills with learning disabled children. This phenomenon is not present in normal, children or mentally retarded children (Lerner, 1971, p. 214).

On the Wechsler Scale of Intelligence for Children, learning disabled children sometimes show significant discrepancies between verbal and performance scores. Children with language disorders may score 10-30 points higher on the performance scale than on the verbal. Those children with perceptual disorders may score 15-40 points higher verbally than on the performance scale. There is often a "scatter" present with a range of 7-12 points between high and low scores on both yerbal and performance scales. If there is a great discrepancy between performance and verbal scores, the higher I.Q. is accepted as an indication of the child's learning potential while the lower I.Q. is a reflection of the child's disabilities (Lerner, 1971; McGrady \& O1son, 1970; Waugh \& Bush, 1971).

On the Stanford-Binet I.Q. test, children with perceptual problems will generally score lower because each set of tests includes at least one item which demands we11-integrated perceptual skills and organization (i.e., picture completion, form discrimination, picture similarities and absurdities, maze tracing, form copying) (Coleman $\&$ Dawson, 1969, p. 244). 
On most readiness tests the total score is usually used for judging whether a child is ready to start reading or not. Coleman points out that a child could score almost zero on copying, but, if his other sub-test scores were strong, his overall score would indicate readiness where in fact the child might be at a severe disadvantage (Ibid., p. 247).

The Illinois Test of Psycholinguistic Abilities (ITPA) provides a profile of auditory-linguistic and visual-linguistic strengths and weaknesses. Two of the twenty subtests discriminate the poor reader. These are the Auditory-Vocal Sequencing subtest for auditory memory and the Visual Motor Sequencing subtest for visual memory (Schwalb, 1969, p. 186). The Auditory Decoding and Visual-Motor Sequencing subtests correctly classify children with minimal brain damage (Lamb, ed. Tarnopo1, 1969, p. 281).

Interestingly enough, Lerner states that the classroom teacher's judgment of certain behavior characteristics was a more reliable technique for identification of children with learning disabilities than neurological, electroencephalographic, opthalmalogical or psychological tests (1971, p. 50).

Many professional people are involved in helping to formulate specific diagnoses of learning disabilities. These include pediatricians, neurologists, eye, ear, nose and throat specialists, social workers, psychologists, psychiatrists, speech specialists and educators (Richards, 1970, p. 565). 


\section{Perception}

Many of the tests discussed pinpoint problems in perception.

"Perception is the processing of sensory data for storage in the brain (Gillespie, 1970, p. 179)." Perceptual impairments are prevalent in learning disabled children. Some of the perceptual problems are visual imperception, auditory imperception, language disorders, and motor problems.

Children who have phychosensory learning disorders (auditory and visual imperception) cannot normally perceive and interpret sensations received through a particular sense channel. They might not be able to "auditorize" from what they see or "visualize" from what they hear (McGrady \& O1son, 1970, p. 582).

Inadequate sensory integration symptoms are: immature postural reactions, poorly developed visual orientation to environmental space, difficulty in the processing of sound into percepts, the tendency toward distractibility, impaired concentration ability, motor or verbal perseveration (Ayres, 1972, p. 342; Waugh \& Bush, 1971, p. 10).

Poor perceptual ability leads to impairments in concept formation. Some characteristic impairments of perception and concept formation are (Lacey, 1970, p. 206; Waugh \& Bush, 1971, p. 7).

1. impaired discrimination of size

2. impaired discrimination of right-left, up-down

3. impaired tactile discrimination

4. poor spatial orientation

5. impaired orientation in time

6. distorted concept of body image

7. impaired judgment of distance

8. impaired discrimination of figure-ground

9. impaired discrimination of part-whole

10. frequent perceptual reversals in reading and writing

11. poor perceptual integration; inability to fuse sensory impressions into meaningful entities. 


\section{Visual Perception}

"The child that cannot properly see (perceive) à triangle, a circle, or a square also cannot properly see a B or D (Shields, p. 23)." Since he does not visualize properly, he neither recognizes words nor is he able to accurately reproduce them (Ibid., p. 23).

Knippner defines sight as sensory acuity and freedom from refraction errors; whereas, vision is defined as perceptual skills involving central nervous system functioning (1971, p. 68). Visual perception, according to Lerner, is made up of the following skills: spatial relations, visual discrimination, figure-ground discrimination, visual closure and object recognition (1971, p. 122).

Visual imperception appears to be the most common difficulty in cases of poor reading, poor spelling, poor writing, reversals, confused handedness, speech problems, uncoordination, spatial confusion, and inability to copy patterns (Gillespie, 1970, p. 180).

Frostig states that there is a medium high correlation between visual perception and beginning reading. This correlation disappears about 3rd Grade (ed. Tarnopol, 1969, p. 225). The poor reader has trouble seeing the order in which the letters come, i.e., visual sequencing (Shields, p. 3).

Lacey recommends that a child with visual imperception should be helped in interpreting and organizing his visual field by at first drastically reducing visual stimuli and then gradually widening the visual field as he successfully.understands and integrates his perceptions (1970, p. 211). 
The Frostig test will detect visual abnormalities, whereas, a test of visual acuity will not (Tarnopol, 1969, p. 192). This test measures four skills (Frostig, ed. Tarnopol, 1969, p. 223).

1. form constancy and size constancy: perception of form or size independent of distance, background pattern, etc.

2. perception of position in space: perception of the direction in which an object is turned.

3. perception of spatial relationships: perception of the relationship of one point in space to another.

4. figure-ground perception: ability to direct the attention to a particular part of the visual field.

\section{Auditory Perception}

Another perceptual problem is auditory impairment. Again this does not refer to children with an actual hearing loss, but an auditory imperception. The clinical signs are: faulty reproduction of verbal speech patterns, inability to comprehend verbal instructions, difficulty in discriminating between sounds of speech, perhaps in understanding what is said to them, lack of attention in class, day dreaming, emotional lability and other behavior problems (Abrams, 1969, p. 577; Gillespie, 1970, p. 180).

Auditory perception involving delayed or retarded speech is the most sensitive indicator of future learning and behavior disorders (Tarnopol, 1969, p. 17). Auditory perception involves auditory discrimination, auditory memory, auditory sequencing, auditory blending (Lerner, 1971, p. 124). Because of an auditory sequencing problem, the poor reading child may have trouble perceiving the order in which a person claps his hands or taps his foot (Shields, p. 3). Many children have no difficulty comprehending single words but are 
limited in the amount of information they can remember. These children have difficulty following directions or remembering a series of things (Zigmond, ed. Tarnopol, 1969, p. 199).

An area of disability related to auditory imperception is language disabilities.

There is growing evidence that auditory and language deficiencies are extremely important factors in learning difficulties and these factors have been neglected in comparison to the emphasis given to aspects of learning (Lerner, 1971, p. 150).

If a child has a language disorder, he will most likely have a learning disability (Lerner, 1971, p. 159). This disability will probably be in learning to read (Abrams, 1969, p. 577). "Delayed speech and language development have brought difficulties in integrating spoken language into written language (Lacey, 1970, p. 208)."

Symptoms of language disorders are:

1. Inner language disorders (preverbal ability to internalize and organize experiences). A disorder at this level refers to the inability to assimilate experiences and is the most severe form of language disturbance.

2. Perceptive language disorders (understanding verbal symbols)-disorder termed receptive aphasia; echolalia.

3. Expressive language disorders (process of producing spoken language) disorder is called expressive aphasia--may depend upon pointing and gesturing to make their wants known (Lerner, 1971, pp. 150-51).

A language disability may be characterized by:

1. Slow to express himself and may stumble over words in doing so.

2. May be very talkative, yet find it difficult to express his ideas.

3. May score below 10 on some WISC verbal subtests and yet function normally on others.

4. Word sequencing problem.

5. Difficulty in acquiring meaning and may not follow directions adequately.

6. Difficult to relate his experiences in normal sequence of verbal expression. 
7. Difficulty in telling time or in determining direction.

8. Slow language development (Waugh \& Bush, 1971).

\section{Motor Problems}

Kinesthetic or motor imperception involves disorders of fine and gross motor coordination. Some of the signs of this impairment are (Gillespie, 1970; Lacey, 1970; Waugh \& Bush, 1971): poor handwriting, general uncoordination and clumsiness, spatial confusion and inability to copy patterns, frequent delayed motor milestones, poor body balance, lack of skills in jumping and skipping, confusion in lateral dominance and directionality, frequent tics and grimaces, hyperactivity or hypoactivity (opposite of hyperactivity).

Kephart identified four motor patterns which have implications

for the education of children with learning problems:

1.: The development of balance and the maintenance of posture. In this way the child systematizes his relationships with objects in his environment.

2. The locomotor skills which move the body through space such as walking, ruming, jumping, skipping, hopping, etc. These are necessary skills if the child is to move with ease and facility and to adjust to changes within his environment.

3. Contact skills of reaching, grasping and releasing. These skills are necessary for the manipulation of objects and for information about figure-ground relationships.

4. Receipt and propulsion skills. Receipt involves making contact with a moving object; propulsion skills are those by which the individual imparts movement. These are the skills that are necessary for understanding movement of objects in the space around him (Gillespie, 1970, p. 18).

From the previous motor patterns, Kephart made up the Purdue

Perceptual Motor Survey which helps to uncover problem areas such as confused directionality, mixed laterality and confusion about body parts (Schwalb, 1969, p. 186). Kephart also formulated a remediation program for these poor motor skills. 
In children who do not seem to prefer one hand over another in writing, training must be used to establish lateral dominance (Shields, p. 9). By directionality confusion is meant differentiation of right from left, e.g., moving eyes from left to right in reading, moving hand from left to right in writing, identification of letters such as $b-d, p-q, g-p, u-n, m-w$, and words such as was-saw, no-on, top-pot. Directionality is also important for place value in arithmetic.

\section{Perceptual Training.}

There is a considerable controversy in the literature concerning the effectiveness of perceptual training on school achievement. Perceptual training means specific exercises to strengthen a perceptual impalrment (visual, auditory, motor).

Frostig formulated tesț to differentiate children with visual imperception from children with normal visual perception. She then formulated a specific remedial program to strengthen the poor visual perception skills. Most of the research indicates that there were no slgnificant gains academically after completion of the Frostig remediation program. Children made significant gains however in visual perception (Krippner, 1971; Leibert \& Shert, 1970; Masland, ed. Tarnopol, 1969).

The Doman-Delacato training program emphasizing motor skills claims that through these exercises neurological organization is changed. This theory attempts to establish in brain-injured, mentally retarded and reading-disabled children the neurological developmental stages observed in normal children. The research has not proven this theory 
(Krippner, 1971, p. 72; Lerner, 1971, pp. 103-5; Masland, ed. Tarnopo1, 1969, p. 78).

The Barsch Movigenic Theory states that difficulties in learning are related to the learners inefficient interaction with space. The omission of certain motor learnings during the infant stages may result in some later difficulty in motor movement or learning. This theory also is not supported by research (Lerner, 1971, pp. 102-3). Getman Visumotor Theory attempts to 11lustrate the developmental sequences of a child's performance in acquiring motor and perceptual ski11s. Each successive stage is dependent upon an earlier level. Getman, an optometrist, incorporated general movement, manipulative skills, visual tracking,- communication skills and reading in his program. Lerner claims there is no empirical evidence that Getman's program helps achieve academic gains (197I, pp. 91-95). Krippner, however, achleved gains with a very small sample (four lst graders) on reading rate, but not reading comprehension by using Getman's training procedure $(1971$, p. 70$)$.

Kephaxt's Perceptual Motor Theory examines the normal sequential development of motor patterns and motor generalizations and compares the motor development of children with learning problems to that of normal children. Reading disabilities often result from learning disorders because of two factors, according to Kephart: 1) incomplete feedback from the muscle system to the brain to compensate for errors in perception, 2) incomplete integration of present and past stimuli (Krippner, 1971, p. 71). In a study by Serwer, Shapiro and Shapiro (1973) four graups were compared. One group was given Kephart's 
training exclusively; the second group was given a combination of Kephart's training and Distar Reading Program; the third group was given only the Distar Reading Program and the fourth group was the control group. The group receiving Kephart's training and the group receiving a combination of Kephart's training and Distar Reading Program did significantly better than only the Distar Reading Program group or the control group in word recognition, handwriting, grossmotor skills, locomotor balance, hand-eye coordination and almost attained statistical significance on spelling. Lerner, however, states that there has been little research evidence to indicate that practice in motor training directly results in increased academic achievement (1971):

Solan and Seiderman state that training in sensory processing, intersensory processing, gross and fine motor development, visual synthesis, visual-motor and visual representation skills and some aspects of visual training particularly hand-eye coordination, do help reading disabled children (1970, p. 635).

Results from a perceptual training program conducted by Ferinden using 11 children showed, after 8 months, significant improvement on the Bender-Gestalt, language abilities on the ITPA subtests and improvement in arithmetic. Reading improvement was statistically significant after 20 months (1971).

In a research project by Ayres, remedial activity for improved sensory integration was accomplished with 128 children. There were statistically significant results on the Wide Range Achievement test in reading and spelling after training daily for 6 months (1972). 
Tarnopol states that exercises help children develop small and large muscle control, laterality and balance (e.g., Kephart, Barsch, Frostig, Doman-Delacato). They help the child improve muscle control, coordination and balance, self-image and social acceptance but there is little evidence that reading ability improves (1969, p. 17).

McGraay \& 01son state that children with primarily language disorders will not respond to perceptual training (1970, p. 588).

\section{Specific Learning Disabilities}

Specific learning disabilities, or special problem areas in school, of ten occur in reading, arithmetic, spelling and handwriting, and usually a combination of these. Reading is the single most important cause of school failure (Sister E. Cronin, ed. Tarnopol, 1969, p. 340). Three per cent of all children are reading one or more years below grade level and are classified as having mild to severe reading disability (Krippner, 1971, p. 66). Reading or language retardation is present when a school child is reading two grades below his mental age (Schwalb, 1969, p. 183). Reading is a process which requires the integration of auditory and visual information (McGrady, 1970). Children with a reading disability were found to be inferior to controls on tests of intersensory functioning. It was evident that the poor readers were deficient in both discrimination and memory aspects of auditory functioning (Zigmond, ed. Tarnopo1, 1969, p. 205). Because of these deficits, a child headed for reading problems cannot approach word recognition by visual recognition patterns alone. He needs to learn phonetic structure to build a sight vocabulary (Sister E. Cronin, ed. Tarnopo1, 1969, p. 337). 
Table 1 shows some statistics compiled by Krippner (1971, p. 67):

TABLE 1

ETIOLOGICAL FACTORS IN THE READING DISABILITIES OF

146 PUPILS OF AVERAGE INTELLIGENCE REFERRED.

TO A READING CLINIC

Impaired acuity of sight

$28.1 \%$

Impaired acuity of hearing

$8.9 \%$

Poor visual-perceptual skills

$62.3 \%$

Poor auditory-perceptual skills

$35.6 \%$

Defective speech

$18.5 \%$

Brain injury

$20.5 \%$

Disturbed neurological organization

$20.5 \%$

Directional confusion (left, right)

$26.0 \%$

Endocrinal malfunctioning

$11.6 \%$

Social immaturity

$17.1 \%$

Neurotic tendencies

$34.2 \%$

Psychotic tendencies

$2.1 \%$

Sociopathic tendencies

$5.5 \%$

Unfavorable educational experience

$56.8 \%$

Cultural deprivation

$6.2 \%$

Some characteristics of children exhibiting a reading disability are (Abrams, 1970; Lacey, 1970; Lerner, 1971; Solan and Seiderman, 1970;

Spraings, ed. Tarnopol; 1969; Waugh \& Bush, 1971):

1. Extremely poor sight vocabulary

2. Oral rereading not improved over oral reading at sight

3. Difficulties in associative learning

4. Performance I.Q. superior to verbal I.Q.

5. Problems in directionality, right-left, orientation

6. Difficulties in concentration

7. Inability to relate information that is heard or read

8. Spatial and temporal confusions

9. Comprehension problems

10. Deficit in conceptual functioning

11. Immediate recall facility may be impaired

12. Auditory difficulties

13. Visual memory difficulties

14. Sequencing difficulties

15. Visual hyperactivity

16. Slow visual processing 
In arithmetic disabilities, the child has problems with leftright discriminations, inversion-reversal tendencies and difficulty in reading and writing number symbols (Homan, 1970, p. 200).

Fine motor handicaps combined with visual perception lapses can make handwriting a very difficult and frustrating task. The incidence of a reading disability alone is relatively rare. "Each category of disability appears to show significant deficits in visualmotor integration and auditory perception (Rice, 1970, p. 153)."

According to Lerner (1971, p. 195). spelling a word is much more difficult than reading a word because of the irregular relationships between the spoken word and the written symbol. The ability to remember how a word looks and how it sounds are extremely important in spelling ability. These are two areas in which learning disabled children of ten do poorly. It has been theorized (Ibid., p. 54) that a child who is strong in auditory perception and in the ability to remember the sounds of words but poor in visual memory and visual learning may misspell the words, but his errors will follow some kind of phonetic generalization; whereas the child whose strengths lie in visual learning and visual memory but is low in auditory perception makes spelling errors that do not follow phonetic generalizations, i.e., he may have all the letters, but in the wrong order. The ability to spell is related to visual sequential memory (Lerner, 1971; Tarnopol, 1969). The subskills needed to spell are: 1) able to read the word, 2) knowledgeable and skillful in certain relationships of phonics and structural analysis, 3) able to apply appropriate 
phonic generalizations, 4) able to visualize the appearance of the word and 5) able to write the word (Lerner, 1971, p. 197).

Furness (1968) states that most people employ a visual approach. to spelling and that people who can recall words vividly in a visual modality will tend to be better spellers. It has been proven that the spelling ability of deaf children is about 150 per cent of that of normal children (Ibid., p. 268). People who do not visualize words rely on auditory impressions of pronunciation, phonetic clues and kinesthetic impressions of how the word feels when it is said and traced or written (Ibid., pp. 268-69). Waugh \& Bush (1971, p. 16) state that a child with a language disability will likely have difficulty in remembering words in spelling, and in the discrimination of words that sound or look similar.

In a study by Hokanson; (1966) the correlation between six perceptual measures and picking out the correctly spelled word was analyzed. Pattern Completion, Memory for Oral Spelling and FigureGround Perception had the highest correlation. With dictated spelling, the perceptual measures, memory for Oral Spelling, Pattern Completion. and Auditory Discrimination correlated most highly. The relative contributions of nine auditory visual discrimination measures, were the largest contributor to the estimate of the spelling of phonetic and non-phonetic words; visual analysis of words was also an important predictor, but I.Q. did not contribute significantly to the predicting of spelling achievement (Aaron, 1954). 
School Intervention Methods

Remediation of the child's learning disabilities can occur in. varied settings. Some schools place these children in small special classes, where they are worked with individually most of the day (Gallagher, 1972; Tarnopol, 1969). Other schools keep the child in the regular classroom for most of the day, but send him for a designated time to a resource teacher who works on his problem areas (Ferinden, 1971; Jacquot, Allen, Landreth, Zepeda, 1970; Sabatino, 1970).

Multi-Sensory Approach to Spelling Remediation

Schwalb (1969, p. 185) recommends a multi-sensory approach for specific remediation of spelling problems. An analysis of how the child learns is always necessary (Lerner, 1971, p. 45), i.e., whether he learns easier through visual, auditory or motor methods. Lerner (1971, p. 119) recommends teaching through the intact modality, strengthening the modality of deficit and using a combination approach.

Sabatino (1970, P. 226) suggests matching teaching methods to the child's strongest area of functioning. Kahn (1969, p. 648) suggests the use of other modalities as an avenue of learning when the more usual modality is impaired. Sister M. Cronin (ed. Tarnopol, 1969, p. 338) states that the use of the auditory-visual-kinesthetic technique is especially helpful in the acquisition of reading, writing and spelling. Lukens (ed. Tarnopol, 1969, p. 361) recommends utilization of multi-sensory procedures whenever a deficit in one 
sensory modality needs training or reinforcement. Lacey (1970, p. 210) states that special materials should be used along with a total sensory teaching approach that involves all receptors and not just vision and audition. Hodges (1968) recommends that in learning to spe11, children should employ the sensory processes of audition, vision and feeling as well as the processes of reasoning and speaking. In a related study, third graders were taught irregular spelling words using a kinesthetic approach. It seemed most beneficial for female subjects in the lower 50 per cent of the I.Q. distribution (Love, 1971). In a multi-sensory approach to reading there was strong evidence that pupils taught by the multi-sensory motor method obtained better reading and spelling scores than did the control pupils, and the method was equally effective for the various I.Q. ranges (Linn \& Ryan, 1968, p. 59).

\section{Grace Fernald (1943) says that:}

Children who do not visualize words must think them in some other terms. They are able to recall words in auditory or kinesthetic terms which are as clear and distinct as the visual (p. 191).

It is Miss Fernald (Ibid., pp. 196-200) who first strongly advocated tracing as one of the steps in teaching children who are poor spellers. Her method was to write the word on a piece of paper and have the child trace over it as many times as he wanted with his fingers. others who advocate tracing in learning to spell are Furness (1968); Gillingham and Stillman (1966); Lerner (1971); Shields (no date).

Maria Montessori (1912, p. 275) in her work with young children taught them the alphabet and sounds by tracing sandpaper letters to add a kinesthetic, tactile dimension to learning. 
This study is formulated by drawing upon the experiences and research of the references cited in this chapter. The numerous references pointing to a multi-sensory approach in learning led to the hypothesis of this study.

\section{Hypothesis}

Learning disabled children who are taught spelling by using sandpaper letters will learn and perform better than those who are taught traditionally. 
CHAPTER III

METHODOLOGY

Population and Sample

The population for the study comprised all the learning disabled children in Berrien County, Michigan, approximately 350 children. There are 44,657 children in this school district. With 350 learning disabled children, the .8 per cent county figure closely resembles the national figure of 1 per cent. Children for the test group were selected from the following randomly selected schools: Niles Eastside School, and the Hollywood School and Stevensville School in the Lakeshore School District. The study involved forty-four children or 13 per cent of all learning disabled children; forty boys and four girls. The children were matched according to sex and age within 6 months. One of each pair was randomly placed in the experimental group and the other in the control group. Two of the pairs were used in a pilot study, and twenty pairs were involved in the major study.

\section{Independent Variables}

The independent variables were: pretest scores, age, I.Q. range and perceptual impairment. The age, I.Q. range and perceptual impairment were given by the resource teachers and special learning disabilities teachers involved. These independent variables were 
chosen to see if any relationship could be found between them and the treatment.

\section{Distribution of the Independent Variables}

In the major sample, there were two eight-year-olds, six nine-year-olds, six ten-year-olds, eight eleven-year-olds, eight twelve-year-olds, eight thirteen-year-olds and two fourteen-year-olds; thirty-eight boys and two girls. Nine of the control group children had I.Q.S under 90; five experimental children had below 90 I.Q.s. Nine control group children had average I.Q.s (90-110) and twelve experimental group children had average I.Q.s. Two control group children had above average I.Q.s (over 110) and three experimental group children had above average I.Q.S.

Ten control group children and nine experimental group children had auditory impairments. Seven control group children and twelve experimental group children had visual impairments. Five control group children and four experimental group children had motor impairments. The total number of children with perceptual impairments is greater than forty because a number of children had more than one impairment.

\section{Procedure}

Children with learning disabilities often are perceptually handicapped, visually or auditorily. Spelling lessons usually rely upon these two sensory modes as the primary teaching method. The control group was taught five new spelling words selected randomly 
from the back of the child's spelling book by the traditional method. The experimental group incorporated added sensory modalities, tactile and kinesthetic perception. This method utilized sandpaper lower case letters, 4-1/2" by 6 " to form the five new spelling words which the child traced as he saw and said the specific letter. The forty students were first given a pretest of the selected words, then after the respective treatment, a posttest was given using the same words. The scores were tabulated for the pretest and the posttest. The errors were analyzed, coded and scored on the following basis:

\begin{tabular}{llll} 
Code & \multicolumn{1}{c}{ Error } & Example & Score \\
\hline 1 & Omission & $\begin{array}{l}\text { afernoon } \\
\text { minunte }\end{array}$ & .89 \\
2 & Extra letter & freind & .83 \\
3 & Reversal & managur & .83 \\
4 & Substitution & jumq & .86 \\
5 & Letter upside-down & or backwards &
\end{tabular}

A percentage score was calculated for each word based on the following formula:

$$
\text { Score }=\frac{\text { number of correct letters }}{\text { number of letters in word }}
$$

Originally the children were to be matched on their respective place in the speller but because of the divergence of the sample in age, grade, school and speller this proved to be an impossibility. From the pilot study, it was learned that five- words was about the maximum number that could be learned at one concentrated sitting. One session with each child caused the least inconvenience to the classroom teacher 
and the child, although two sessions would have been interesting to test long-term recall. Each session usually lasted less than 30 minutes.

The structure of the lesson for the experimental group follows:

A. Introduction

1. Get acquainted with the child and explain what will take place.

2. Give pretest pronouncing each word distinctly and using it in a sentence.

B. Spe11ing Lesson

1. The child pronounces the word.

2. The meaning of the word is checked with the child.

3. The child looks at the word and spells it; if the word is long, he breaks it into syllables.

4. The child looks at the word, closes his eyes and spells it.

5. The child traces each sandpaper letter of the word with his fingers. He says the letter as he traces it.

6. The child closes his eyes and traces the sandpaper letters of the word saying each letter.

7. The child writes the word.

C. Conclusion

1. Posttest is given using each word in a sentence.

2. The child is shown his errors, if any, praised for his effort and thanked for his cooperation.

The procedure for the control group was exactly the same as the experimental group except Steps 5 and 6 were omitted.

The treatment was administered to both the experimental and control groups by the researcher. 
An observation made in teaching the lesson was that Step 5, tracing each letter, involved primarily the tactile perception with the child usually using one finger to trace the letters. On Step 6, however, when the child closed his eyes and traced the letters, he was involved more kinestheticaliy as he used two or three fingers and moved his whole hand and arm. 
CHAPTER IV

ANALYSIS OF THE DATA

\section{Pretest-Posttest Scores Analysis}

Forty students were taught five spelling words. Twenty students were taught using the traditional method and the other twenty students were taught using a multi-sensory approach. These children were matched on age and sex.

Table 2 is a summary of the data generated by these forty students. The independent variables are the pretest score, I.Q. range, age and perceptual impairment. The dependent variables are: the posttest score and the difference between the pretest and posttest scores. Table 3 shows the means and standard deviations for the control group and experimental group.

A stepwise regression analysis was performed on the preceding data. In the regression analysis, when pretest score was entered a .6374 correlation to posttest was established. The second variable to be added to regression analysis was the treatment (experimental or control). Treatment added to the correlation only slightly bringing the multiple correlation to .6408 . At the next step, age was added and brought the multiple correlation to .6423; the last variable added was I.Q. range which brought the multiple correlation to .6444 . It is an obvious conclusion that the pretest score would be the highest 
TABLE 2

SUMMARY OF THE DATA

\begin{tabular}{|c|c|c|c|c|c|c|c|c|c|c|c|}
\hline \multirow{2}{*}{$\begin{array}{c}\text { Student } \\
\text { 非 }\end{array}$} & \multicolumn{4}{|c|}{ Control } & \multirow{2}{*}{$\frac{}{\text { Diff. }}$} & \multirow[b]{2}{*}{ Age } & \multicolumn{5}{|c|}{ Experimental } \\
\hline & $\begin{array}{l}\text { Pre- } \\
\text { test }\end{array}$ & $\begin{array}{c}\text { I.Q. } \\
*\end{array}$ & $\begin{array}{c}\text { P.I. } \\
+ \\
\end{array}$ & $\begin{array}{l}\text { Post- } \\
\text { test }\end{array}$ & & & $\begin{array}{l}\text { Pre- } \\
\text { test }\end{array}$ & $\begin{array}{c}I_{.}{ }_{0} \\
*\end{array}$ & $\begin{array}{r}\text { P.I. } \\
+ \\
\end{array}$ & $\begin{array}{l}\text { Post- } \\
\text { test }\end{array}$ & Diff. \\
\hline 1 & 2.25 & 100 & A & 4.20 & 1.95 & 14 & 2.55 & 90 & $A-V$ & 2.90 & .35 \\
\hline 2 & 3.07 & 100 & $\mathrm{v}$ & 4.75 & 1.68 & 13 & 3.02 & 100 & A & 4.75 & 1.73 \\
\hline 3 & 3.42 & 90 & $\dot{\mathrm{V}}$ & 4.83 & 1.41 & 13 & 2.54 & 90 & & 4.20 & 1.66 \\
\hline 4 & 3.43 & 90 & v & 5.00 & 1.57 & 13. & 1.07 & 100 & & 2.50 & 1.43 \\
\hline 5 & 2.87 & 90 & $A-V-M$ & 4.39 & 1.52 & 13 & 3.10 & 90 & $A-V$ & 4.54 & 1.44 \\
\hline 6 & 3.00 & 90 & A $\because$ & 5.00 & 2.00 & 12 & 2.72 & 100 & A & 4.40 & 1.68 \\
\hline 7 & 4.43 & 100 & & 5.00 & .57 & 12 & 3.25 & 100 & $A-M$ & 3.81 & .56 \\
\hline 8 & 1.98 & 90 & A & 2.79 & .81 & 12 & 2.71 & 100 & $\mathrm{~V}$ & 4.32 & 1.61 \\
\hline 9 & $3: 93$ & 90 & A & 5.00 & 1.07 & 12 & 3.05 & 100 & V & 4.50 & 1.45 \\
\hline 10 & 1.23 & 90 & A & 2.50 & 1.27 & 11 & .20 & 100 & A & 2.77 & 2.57 \\
\hline 11 & 3.97 & 100 & M & 4.80 & .83 & 11 & 4.41 & 110 & A & 5.00 & .59 \\
\hline 12 & 3.39 & 100 & $A-V$ & 4.28 & .89 & 11 & 3.25 & 100 & $\mathrm{~V}-\mathrm{M}$ & 4.40 & 1.15 \\
\hline 13 & 3.40 & 100. & V. & 4.03 & .63 & 11 & 3.49 & 100 & $\mathrm{~V}$ & 5.00 & 1.51 \\
\hline 14 & 3.59 & 100 & $A$ & 4.89 & 1.30 & 10 & 2.74 & 90 & $\mathrm{~V}$ & 3.95 & 1.21 \\
\hline 15 & 1.63 & 100 & & 5.00 & 3.37 . & 10 & 2.35 & 100 & $\mathrm{~V}-\mathrm{M}$ & 4.20 & 1.85 \\
\hline 16 & 3.66 & 110 & V & 4.75 & 1.09 & 10 & 2.64 & 110 & $\mathrm{~V}$ & 4.64 & 2.00 \\
\hline 17 & 3.20 & 100 & A & 3.85 & .65 & 9 & 1.48 & 100 & $A-V$ & 4.42 & 2.94 \\
\hline 18 & .20 & 90 & M & 4.30 & 4.10 & 9 & 2.00 & 90. & $A-V$ & 4.25 & 2.25 \\
\hline 19. & 3.50 & 110 & A & 4.40 & .90 & 9 & 2.30 & 100 & $\dot{\mathrm{V}}$ & 2.25 & -.05 \\
\hline 20 & .91 & 90 & $M$ & 1.84 & .93 & 8 & 2.67 & 110 & $\mathrm{M}$ & 3.58 & .91 \\
\hline Totals & 57.06 & & & 85.60 & 28.54 & & 51.54 & & & 80.38 & 28.84 \\
\hline
\end{tabular}

*I.Q. Range: $90=$ Below Average, $100=$ Average, $110=$ Above Average

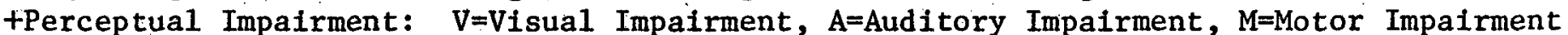


TABLE 3

MEANS AND STANDARD DEVIATIONS

\begin{tabular}{lllr}
\hline \multirow{2}{*}{ Group } & Variable & Mean & $\mathrm{s}$ \\
\hline \multirow{2}{*}{ Control } & Pretest & 2.85 & 1.12 \\
& Posttest & 4.28 & .91 \\
& Difference & 1.43 & .90 \\
Experimental & Pretest & & .90 \\
& Posttest & 4.58 & .81 \\
& Difference & 1.44 & .67 \\
\hline
\end{tabular}

predictor of the posttest score. The $F$ value for the pretest is the only one that is statistically significant at the .01 level as shown on Table 4. Table 5 gives the correlation matrix for the data.

The next test made on the data was a stepwise regression analysis using the difference as the dependent variable. Again pretest score was the best predictor of the difference score having a correlation of .5819 . Variable 4 or treatment, when added, brought the correlation up to .5859 . Variable 6, age, brought the correlation to .5874 and I.Q. brought it to .5899. The $F$ Value of the pretest only achieved a significant $F$ Value as seen on Table 6 .

The order of entry influenced the regression weights so a stepwise regression was used eliminating pretest, age and I.Q. In this case, the treatment was entered first bringing a .1538 correlation. Variable 7, impairment was then added bringing the correlation only up slightly to .1601 . These values of $\mathrm{R}$ indicate little contribution of treatment or impairment to the prediction of the posttest scores. There was no statistical significance to the F Values shown in Table 7 . 
TABLE 4

SUMMARY TABLE OF STEP-WISE REGRESSION NO. 1

\begin{tabular}{clcc}
\hline $\begin{array}{c}\text { Step } \\
\text { \# }\end{array}$ & \multicolumn{1}{c}{$\begin{array}{c}\text { Variable } \\
\text { Entered }\end{array}$} & $\begin{array}{c}\text { Multiple r for } \\
\text { Predicting Post- } \\
\text { test Scores }\end{array}$ & F Value \\
\hline & Pretest & .6374 & $25.9976 *$ \\
1 & Contro1-Experimental & .6408 & .2800 \\
2 & Age & .6423 & .1111 \\
3 & I.Q. Range & .6444 & .1617 \\
4 & & & \\
\hline
\end{tabular}

* Significant at .01 level

TABLE 5

CORRELATION MATRIX

\begin{tabular}{|c|c|c|c|c|c|c|c|}
\hline Variable & 1 & 2 & 3 & 4 & 5 & 6 & 7 \\
\hline $\begin{array}{l}1 \\
2 \\
3 \\
4 \\
5 \\
6 \\
7\end{array}$ & 1.000 & $\begin{array}{r}.637 \\
1.000\end{array}$ & $\begin{array}{r}-.582 \\
.256 \\
1.000\end{array}$ & $\begin{array}{r}-.138 \\
-.154 \\
.013 \\
1.000\end{array}$ & $\begin{array}{r}.284 \\
.191 \\
-.153 \\
.192 \\
1.000\end{array}$ & $\begin{array}{r}.239 \\
.191 \\
-. .101 \\
-.000 \\
-.0323 \\
1.000\end{array}$ & $\begin{array}{r}.160 \\
.027 \\
-.047 \\
.119 \\
-.148 \\
.048 \\
1.000\end{array}$ \\
\hline
\end{tabular}

KEY: 1 = Pretest

2 = Posttest

$3=$ Difference

$4=$ Control or Experimental

$5=I . Q$. Range

6 = Age

7 = Impairment (total number). 
TABLE 6

SUMMARY TABLE OF STEP-WISE REGRESSION NO. 2

\begin{tabular}{clcr}
\hline $\begin{array}{c}\text { Step } \\
\text { \# }\end{array}$ & \multicolumn{1}{c}{$\begin{array}{c}\text { Variable } \\
\text { Entered }\end{array}$} & $\begin{array}{c}\text { Multiple r for } \\
\text { Predicting Post- } \\
\text { test Scores }\end{array}$ & F Value \\
\hline 1 & Pretest & .5819 &. \\
2 & Control-Experimental & .5859 & $19.4575 *$ \\
3 & Age & .5874 & .2617 \\
4 & I.Q. Range & .5899 & .0937 \\
& T. & .1582 \\
\hline
\end{tabular}

* Significant at the .01 level

TABLE 7

SUMMARY TABLE OF STEP-WISE REGRESSION NO. 3

\begin{tabular}{|c|c|c|c|}
\hline $\begin{array}{l}\text { Step } \\
\text { \# }\end{array}$ & $\begin{array}{l}\text { Variable } \\
\text { Entered }\end{array}$ & $\begin{array}{l}\text { Multiple } r \text { for } \\
\text { Predicting Post- } \\
\text { test Scores }\end{array}$ & F Value \\
\hline $\begin{array}{l}1 \\
2\end{array}$ & $\begin{array}{l}\text { Control-Experimental } \\
\text { Impairment }\end{array}$ & $\begin{array}{l}.1538 \\
.1606\end{array}$ & $\begin{array}{l}.9212 \\
.0807\end{array}$ \\
\hline
\end{tabular}

When this same test was made using the difference as the dependent variable and treatment and impairment as the independent variables, the results were similar as reported in Table 8. The only difference noted. was that impairment entered before treatment.

TABLE 8

SUMMARY TABLE OF STEP-WISE REGRESSION NO. 4

\begin{tabular}{cccc}
\hline \hline $\begin{array}{l}\text { Step } \\
\#\end{array}$ & $\begin{array}{l}\text { Variable } \\
\text { Entered }\end{array}$ & $\begin{array}{c}\text { Multiple r for } \\
\text { Predicting Post- } \\
\text { test Scores }\end{array}$ & F Value \\
\hline 1 & Impairment & .0470 & .0840 \\
2 & Control-Experimental & .0504 & .0124 \\
\hline
\end{tabular}


An analysis of covariance with multiple covariates was next performed. The criterion was the posttest score and the covariates were pretest score, I.Q. range and number of impairments for the control and the experimental group. By this means, we were able to compare posttest scores as they were predicted to be if the groups were equal on pretest, I.Q. and number of impairments. The results were: F test for regression was .19576 , indicating the validity of the assumption of equal regression in the groups. The $F$ ratio for the hypothesis of equal group effects was .39 , which was not significant. An analysis of covariance was performed on the differences between the scores of the control and experimental groups for children with an auditory impairment and for children with a visual impairment. As the results show in Table 9, the differences were not statistically significant.

\section{TABLE 9}

F RATIOS FOR SUBGROUPS

\begin{tabular}{ll}
\hline Average I.Q. Range & $\mathrm{F}=.612$ \\
Auditory Impairment & $\mathrm{F}=.404$ \\
Visual Impairment & $\mathrm{F}=.198$ \\
\hline
\end{tabular}

\section{Types of Eiror Scores Analysis}

The types of exror were categorized and counted for the control and experimental groups to see if one type of error might be corrected by the treatment. Table 10 describes the types of error, and Table 11 summarizes the types of error scores. 
TABLE 10

TYPES OF ERROR

1 - letter missing

2 - letter too many

3 - reversal

4 - letter substitution

5 - letter upside down, sidewards or backwards (correct letter)

The most frequent errors made were errors 1 and 4. As mentioned in the research, children with visual impairments made more errors as counted on the pretest than children with auditory or motor impairments.

$$
\begin{aligned}
& \text { Visual impairments }-11.16 \text { errors (average) } \\
& \text { Motor impairments }-10.56 \text { errors (average) } \\
& \text { Auditory impairments }-10.06 \text { errors (average) }
\end{aligned}
$$

Children with visual impairments made more type 1,3 and 4 errors and children with auditory impairments and visual impairments both had the same number of type 2 errors.

An analysis of covariance was performed on the difference between the control and experimental scores of type 1 error, i.e., letter missing, and on type 4 error, i.e., letter substitution. Table 12 shows the results which were not statistically significant. An analysis of covariance was performed on the difference between the control and experimental scores for Type 1 Errors for children with average I.Q., below average I.Q., auditory impairment, motor impairment and visual impairment. Table 13 summarizes the findings. These results were not statistically significant. 
TABLE 11

TYPES OF ERROR SCORES

\begin{tabular}{|c|c|c|c|c|c|c|c|c|c|c|c|c|c|c|c|c|c|c|c|c|}
\hline \multirow[b]{3}{*}{$\begin{array}{c}\text { Types of } \\
\text { Errors }\end{array}$} & \multicolumn{10}{|c|}{ Cóntrol } & \multicolumn{10}{|c|}{ Experimental } \\
\hline & \multicolumn{5}{|c|}{ Pretest } & \multicolumn{5}{|c|}{ Posttest } & \multicolumn{5}{|c|}{ Pretest } & \multicolumn{5}{|c|}{ Posttest } \\
\hline & 1 & 2 & 3 & 4 & 5 & 1 & 2 & 3 & 4 & 5 & 1 & 2 & 3 & 4 & 5 & 1 & 2 & 3 & 4 & 5 \\
\hline 1 & 4 & 0 & 1 & 3 & 0 & 3 & 0 & 0 & 1 & 0 & 2 & 0 & 1 & 8 & 0 & 2 & 2 & 1 & 4 & 0 \\
\hline 2 & 2 & 0 . & 1 & 5 & 0 & 0 & 0 & 0. & 1 & 0 & 2 & 2 & 0 & 3 & 0 & 0 & 0 & 0 & 1 & 0 \\
\hline 3 & 3 & 1 & 1 & 6 & 0 & 1 & 0 & 0 & 0 & 0 & 12 & 0 & 0 & 5 & 0 & 4 & 0 & 0 & 2 & 0 \\
\hline 4 & 4 & 0 & 0 & 6 & 0 & 0 & 0 & 0 & 0 & 0 . & 15 & 0 & 1 & 10 & 0 & 8 & 0 & 0 & 8 & 0 \\
\hline 5 & 4 & 0 & 0 & 10 & 0 & 3 & 0 & 0 & 1 & 0 & 3 & 0 & 2 & 4 & 0 & 0 & 0 & 0 & 3 & 0 \\
\hline 6 & 5 & 0 & 0 & 4 & 1 & 0 & 0 & 0 & 0 & 0 & 3 & 1 . & 1 & 5 & 1 & 0 & 0 & 2 & 1 & 0 \\
\hline 7 & 2 & 0 & 1 & 1 & 0 & 0 & 0 & 0 & 0 & 0 & 5 & 1 & 1 & 5 & 0 & 2 & 2 & 2 & 2 & 0 \\
\hline 8 & 13 & 0 & 1 & 7 & 0 & 5 & 0 & 0 & 10 & 0 & 8 & 0 & 1 & 7 & 0 & 2 & 0 & 1 & 2 & 0 \\
\hline 9 & 2 & 0 & 1 & 2 & 0 & 0 & 0 & 0 & 0 & 0 & 5 & 2 & 2 & 1 & 0 & 2 & 0 & 1 & 0 & 0 \\
\hline 10 & 2 & 0 & .2 & 0 & 0 & 5 & 0 & 1 & 1 & 0 & 4 & 3 & 0 & $\overline{0}$ & 0 & 3 & 0 & 0 & 2 & 0 \\
\hline 11 & 2 & 1 & 0 & 3 & 0 & 0 & 0 & 0 & 1 & 0 & 2 & 1 & 0 & 1 & 0 & 0 & 0 & 0 & 0 & 0 \\
\hline 12 & 5 & 1 & 1 & 4 & 0 & 1 & 1 & 0 & 2 & 0 & 6 & 1 & 1 & 4 & 0 & 1 & 1 & 0 & 2 & 0 \\
\hline 13 & 5 & $\overrightarrow{1}$ & 0 & 3 & 0 & 0 & 2 & 1 & 2 & 0 & 1 & 0 & 2 & 5 & 0 & 0 & 0 & 0 & 0 & 0 \\
\hline 14 & 5 & 1 & 0 & 1 & 0 & 1 & 0 & 0 & 0 & 0 & 9 & 1 & 1 & 3 & 0 & 1 & 0 & 0 & 2 & 2 \\
\hline 15 & 5 & 0 & 0 & 5 & 0 & 0 & 0 & 0 & 0 & 0 & 6 & 0 & 1 & 5 & 0 & 0 & 2 & 1 & 1 & 0 \\
\hline 16 & 5 & 1 & 0 & 2 & 0 & 0 & 0 & 0 & 1 & 0 & 4 & 2 & 1 & 6 & 0 & 1 & 1 & 0 & 0 & 0 \\
\hline 17 & 3 & $\overline{0}$ & 1 & 4 & 0 & $i$ & 1 & 0 & 3 & 0 & 1 & 0 & 2 & 6 & 0 & 0 & 0 & 0 & 2 & 0 \\
\hline 18 & 6 & 0 & 0 & 2 & 0 & 1 & 0 & 0 & 1 & 1 & 9 & 0 & 1 & 2 & 1 & 3 & 0 & 0 & 0 & 0 \\
\hline 19 & 2 & 1 & 0 & 3 & 1 & 1 & 0 & 0 & 2 & 0 & 6 & 0 & 0 & 5 & 1 & 1 & 0 & 1 & 11 & 0 \\
\hline 20 & 10 & 0 & 0 & 5 & 0 & 6 & 0 & 0 & 6 & 0 & 2 & 1 & 1 & 4 & 0 & 1 & 1 & 1 & 2 & 0 \\
\hline Totals & 89 & 7 & 10 & 88 & 2 & 28 & 4 & 2 & 32 & 1 & 105 & 15 & 19 & 89 & 3 & 31 & 9 & 10 & 45 & 2 \\
\hline Means & 4.45 & .35 & .5 & 4.4 & .1 & 1.4 & .2 & .1 & 1.6 & .05 & 5.25 & .75 & .95 & 4.45 & .15 & 1.55 & .45 & .5 & 2.25 & .1 \\
\hline
\end{tabular}


TABLE 12

F RATIOS OF TYPE 1 AND TYPE 4 ERROR SCORES

Type 1 errors

F Ratio $=.151$

Type 4 errors

F Ratio $=.653$

TABLE 13

SURMARY OF F RATIOS OF SUBGROUPS

\begin{tabular}{ll}
\hline Average I.Q. & F Ratio $=.005$ \\
Below Average I.Q. & F Ratio $=.604$ \\
Auditory Impairment & F Ratio $=.399$ \\
Motor Impairment & F Ratio $=.983$ \\
Visual Impairment & F Ratio $=.168$ \\
\hline
\end{tabular}




\section{CHAPTER V}

\section{SUMMARY AND CONCLUSIONS}

In the preceding chapter it was shown that the experimental group did not do significantly better than the control group. It would be premature however to conclude that adding a tactile, kinesthetic element to teaching spelling is worthless. The research cited in the review of the literature is convincing in showing that a multi-sensory approach helps children with learning problems.

Some possible reasons why the results of this study showed no significant improvement of the experimental group are offered below:

1. One thirty-minute lesson is not long enough to achieve consistent gains.

2. A multi-sensory approach should be continued day after day before a judgment is made as to its effectiveness.

3. Children have poor tactile, kinesthetic sense from disuse.

4. Some children did not try to do their best.

5. The sandpaper letters were novel and distracting for some students and they might need more than thirty minutes to get used to them so that they could benefit from them.

6. Learning disabled children are too diverse a group to benefit uniformly from one method of teaching; i.e., each child must be taught individually. 
It is suggested that future studies be done with a different time schedule. Perhaps tracing in the air, or tracing over other material, or first wetting the finger with cold water to stimulate the tactile sense might prove more effective.

Although none of the F Ratios were statistically significant some trends might prove significant after time. Children of average intelligence within the age group of 10, 11 and 12 years old seemed to benefit more from the experimental treatment than the control group treatment. In examining Type 4 Errors (substitution) the children in the experimental group corrected this error more frequently on the posttest. The children with below average I.Q. and motor impairment showed more corrections of Type 1 Error (letter missing) on the posttest if they were in the experimental group.

In conclusion, the hypothesis of this study, i.e., that learning disabled children who were taught spelling by using sandpaper letters will learn and perform better than those who were taught traditionally, was not supported by the data. This hypothesis, however, should not be totally discounted without first testing it with other research designs. Because one of the goals of education is to help each child strive to reach his full potential, it is imperative that those working with these children be helped to find the best methods of teaching effectively. 


\section{BIBLIOGRAPHY}

Aaron, Ira Edward. "The Relationship of Auditory-Visual Discrimination to Spelling Ability." Ph.D. Dissertation, University of Minnesota, 1954.

Abrams, Jules C. "An Interdisciplinary Approach to Learning Disabilities." Journal of Learning Disabilities 2 (Nov. 1969): $575-78$.

- "Parental Dynamics--their Role in Learning Disabilities." The Reading Teacher 23 (May 1970): 751-55.

Anderson, Robert P. "A Neuropsychogenic Perspective on Remediation of Learning Disabilities." Journal of Learning Disabilities 3 (March 1970): 143-48.

Ayres, A. Jean. "Improving Academic Scores through Sensory Integration." Journal of Learning Disabilities 5. (June/Ju1y 1972): 338-43.

Brown, George W. "Suggestions for Parents." Journal of Learning Disabilities 2 (February 1969): 97-106.

Coleman, Howard M. \& Dawson, Sarah T. "Educational Evaluation and Visual Perceptua1-Motor Dysfunction." Journal of Learning Disabilities 2 (May 1969): 242-51.

Ferinden, W. B., VanHandel, Donald, Kovalinsky, Thomas. "Supplemental Instructional Program for Children with Learning Disabilities." Journal of Learning Disabilities 4 (April 1971): 193-203.

Fernald, Grace. Remedial Techniques in Basic School Subjects. New York and London: McGraw-Hill Book Co., 1943.

Froomkin, Joseph. Report to the President's Commission on School Finance, Estimates and Projections of Special Target Group Populations in Elementary and Secondary Public Schools. Washington, D.C.: Froomkin Inc., 1972.

Furness, Edna Lue. "Pupils, Teachers, and Sensory Approaches to Spe11ing." Education 88 (February 1968): 267-73.

Gallagher, James J. "The Special Education Contract for Mildly Handicapped Children.". Exceptional Children 38 (March 1972): 527-35. 
Gillespie, Margaret: "The Perceptual Aspects of Special Education." National Catholic Guidance Conference Journal 14 (Spring 1970): $179-82$.

Hodges, Richard E. What's New in Language Arts. University of Chicago: ERIC Document Reproduction Service, ED 017 489, 1968.

Hokanson, Edward. "The Relationship between Selected Visual and Auditory Perception Capabilities and Spelling Capability as Measured by Tests Requiring Spelling Recognition and Spelling Reca11." Ph.D. Dissertation, University of Minnesota, 1966.

Homan, Doris Ruth. "The Child with a Learning Disability in Arithmetic." The Arithmetic Teacher 17 (March 1970): 199-203.

Jacquet, William, Allen, Louise, Landreth, Gary, Zepeda, Ruth. "Learning Disabilities a Team Approach." The Elementary School Journal 70 (February 1970): 248-52.

Kahn, J. P. "The Emotional Concomitants of the Brain-Damaged Child." Journa1 of Learning Disabilities 2 (December 1969): 644-51.

Krippner, Stanley. "On Research in Visual Training and Reading Disability." Journal of Learning Disabilities 4 (February 1970): 68-75.

Lacey, Harvey M. "A Meaningful Diagnosis or an Irrelevant Label?" Child Welfare 4 (April 1970): 205-11.

Leibert, Robert, Sherk, John. "Three Frostig Visual Perception Subtests and Specific Reading Tasks for Kindergarten, First and Second Grade Children." The Reading Teacher 24 (1970): 130-37.

Lerner, Janet $W$. Children with Learning Disabilities. Boston: Houghton, Mifflin Co., 1971.

Linn, J. R., Ryan, T. J. "Multi-Sensory-Motor Method of Teaching Reading." Journal of Experimental Education 36 (Summer 1968): 57-9.

Love, Franklin Dean. "Study with Third Grade Children of the Effects of Intensified Kinesthetic Sensory Involvement on the Learning of Selected Irregular Spellings." Ph.D. Dissertation, University of Washington, 1971.

McGrady, Harold J., Olson, Don A. "Visual and Auditory Learning Processes in Normal Children and Children with Specific Learning Disabilities." Exceptional Children 36 (April 1970): 581-89. 
Montessori, Maria. The Montessori Method. New York: Frederick A. Stokes Co., 1912 .

Rice, Donald. "Learning Disabilities: An Investigation in Two Parts." Journal of Learning Disabilities 3 (March 1970): 149-55.

Richards, H. E. "Helping the Learning Disabled through Existing Community Services." Journal of Learning Disabilities (November 1970): 563-69.

Sabatino, David. "Auditory and Visual Perceptual Behavioral Function of Neurologically Impaired Children." Perceptual and Motor Skills 29 (1969): 35-40.

Sabatino, David, Hayden, David. "Prescriptive Teaching in a Summer Learning Disabilities Program." Journal of Learning Disabilities 3 (April 1970): 220-26.

Schwalb, Eugene, Blau, Harold, Blau, Harriet. "Child with Brain Dysfunction." Journal of Learning Disabilities 2 (April 1969): 182-88.

Serwer, Blanche, Shapiro, Bernard, Shapiro, Phyllis. "The Comparative Effectiveness of Four Methods of Instruction on the Achievement of Children with Specific Learning Disabilities."' Journal of Special Education 7 (Fal1 1973): 241-49.

Shields, 0. L. "Learning Disabilities A Handbook for Tutors." Jefferson County Schools, Louisville, Ky. (Mimeographed.)

Solan, Harold, Seiderman, Arthur. "Case Report on a Grade One Child before and after Perceptual-Motor Training." Journal of Learning Disabilities 3 (December 1970): 635-39.

Tarnopol, Lester, ed. Learning Disabilities: Introduction to Educational and Medical Management. Springfield, I11.: Charles C. Thomas Publisher, 1969.

Waugh, Kenneth, Bush, Wilma Jo. Diagnosing Learning Disorders. Columbus, Ohio: Charles E. Merrill Publishing Co., 1971. 